\title{
Correction to: Connecting Politics and Society: A Way Forward for Think Tanks
}

\author{
Pol Morillas
}

\section{Correction to:}

Connecting Politics and Society: A Way Forward for Think Tanks in: J. McGann, The Future of Think Tanks and Policy Advice Around the World, https://doi.org/10.1007/978-3-030-60379-3_8

The original version of this chapter was inadvertently published with an incorrect chapter author name "Pol Morrillas" instead of "Pol Morillas", which have now been corrected. The correction to the book have been updated with the changes.

The updated version of this chapter can be found at https://doi.org/10.1007/978-3-030-60379-3_8

(C) The Author(s) 2021, corrected publication 2021 